\title{
Role of the olfactory systems and importance of learning in the ewes' response to rams or their odors
}

\author{
Hélène GELEZ, Claude FABRE-NYS* \\ Station de Physiologie de la Reproduction et des Comportements, UMR 6175 INRA-CNRS-Université \\ de Tours-Haras Nationaux, 37380 Nouzilly, France
}

\begin{abstract}
In sheep, exposure of seasonally anestrous females to the male or its fleece results in activation of luteinizing hormone (LH) secretion and synchronized ovulation. The study of the neural pathways involved in this phenomenon, commonly named "male effect", show that the main olfactory system plays a critical role in the detection and the integration of the male odor. The accessory olfactory system participates in the perception of the ram odor but does not seem necessary for the endocrine response. According to the hypothesis that the neuroanatomical differences between the two olfactory systems could be associated with different functional roles, we investigated the importance of sexual experience and learning processes in the male effect. Our results showed that female responses depend on previous sexual experience. We also demonstrated that the LH response to male odor could result from an associative learning process. The aim of the present report was to summarize our current knowledge concerning the "male effect" and in particular to clarify the role of sexual experience and learning in the processes involved in this effect.
\end{abstract}

ovine / male effect / LH / olfaction / experience

\section{INTRODUCTION}

Among the different factors involved in the control of reproduction, social interactions can greatly influence and modify the reproductive events, from sexual postures to endocrine regulations. Indeed, depending on the biological context, the effects of social interactions can result in inhibition of reproduction in some individuals of the group or, in stimulation and synchronization of neuroendocrinology and behavior. In rodents, housing together individuals in unisex groups results in modification of the estrous cycle of females [1-3] and testicular development in males [4]. Contacts between sexual partners can also modify the reproductive processes and affect most stages of reproduction: acceleration of pu- berty and testicular growth $[5,6]$, induction and synchronization of ovulation and estrus [7], blockage of pregnancy [8]. It has been demonstrated that in most cases, the physiological response is initiated by a rapid change in hormonal concentrations (luteinizing hormone $(\mathrm{LH})$ and prolactin in females, $\mathrm{LH}$ and testosterone in males) $[9,10]$. These phenomena have been extensively studied in rodents but they are not restricted to these species. In sheep and goats, the introduction of males in a flock of seasonally anoestrous females results in activation of the secretion of $\mathrm{LH}$ and synchronized ovulation $[11,12]$. This phenomenon, commonly called the "male effect", is frequently used in sheep and goat husbandry to advance and synchronize reproduction [13].

\footnotetext{
* Corresponding author: fabre@tours.inra.fr
} 
Among the different sensory signals exchanged between the individuals, olfactory cues play a preponderant role in mammals since they can mimic most of the behavioral and physiological changes induced by interactions between conspecifics of the same sex or between sexual partners. It has been reported in many species that chemical signals serve as sexual attractants, and promote sexual arousal, appetitive and precopulatory postures and mating behavior (rat [14], mouse [15], hamster [16], elephant [17], rhesus macaque [18]). These chemosignals can also modify the physiology and neuroendocrine state (mouse [19], rat [20], hamster [9], prairie vole [21]). In sheep, ram fleece activates LH secretion in anestrous ewes [22].

However, in a flock or a group of ewes, not all the females exhibit an LH increase in response to the ram or its fleece. Several factors account for the variability of the response: the race, the period of the year, the male sexual activity, etc. Two arguments let us hypothesize that sexual experience can also be a critical factor, especially for the response to the ram odor. Firstly, preliminary data suggest that the male fleece is ineffective to activate the $\mathrm{LH}$ secretion in sexually naive ewes [23]. However, these results remain unclear and need confirmation. Our second argument came from our studies examining the neural pathways involved in the processes of the male effect. In mammals, olfactory signals are detected and integrated by two olfactory systems: the accessory and the main olfactory systems, which are anatomically and functionally separated and which possess their own receptors and central pathways. The accessory olfactory system is essentially connected to hypothalamic structures: the axons of the neuroreceptors of the vomeronasal organ (VNO) project to the accessory olfactory bulb (AOB) which in turn projects to the medial amygdala which has direct connections to the ventromedial hypothalamic nucleus and the preoptic area (rat [24], hamster [25, 26], sheep [27]). On the contrary to the accessory system, the main olfactory system is linked to several cortical areas: the main olfactory bulb (MOB) projects to the cortical amygdala, to the piriform cortex which is connected via the thalamus to the orbitofrontal and insular cortices, and to the entorhinal cortex which is connected to the hippocampus [25-27]. According to some authors, the neuroanatomical differences between the two olfactory systems could be associated with different functional roles [28-30]. It has been postulated that the vomeronasal neural pathway that bypasses the cognitive regions of the brain, could be implicated in the detection and integration of chemochemicals eliciting preprogrammed and stereotyped responses. This has been verified in rodents since most chemosignals are detected by the accessory olfactory system and frequently induce stereotyped and automatic responses [29] (Tab. I). In contrast, the numerous cortical areas belonging to the main olfactory system could provide for elaborate treatment of the olfactory information, involving cognitive or learning mechanisms. According to our findings showing that the main olfactory system plays a critical role in the detection of the male odor, we hypothesized that sexual experience and learning can modulate the ewes ' responses to the male effect.

The aim of the present report was to present the data that conduct us to this hypothesis and the procedures we used to assess the role of sexual experience and learning in the processes involved in the male effect.

\section{DESCRIPTION OF THE MALE EFFECT}

\subsection{Endocrine response}

Sheep are seasonal breeders and during the period of anestrus, ewes do not 


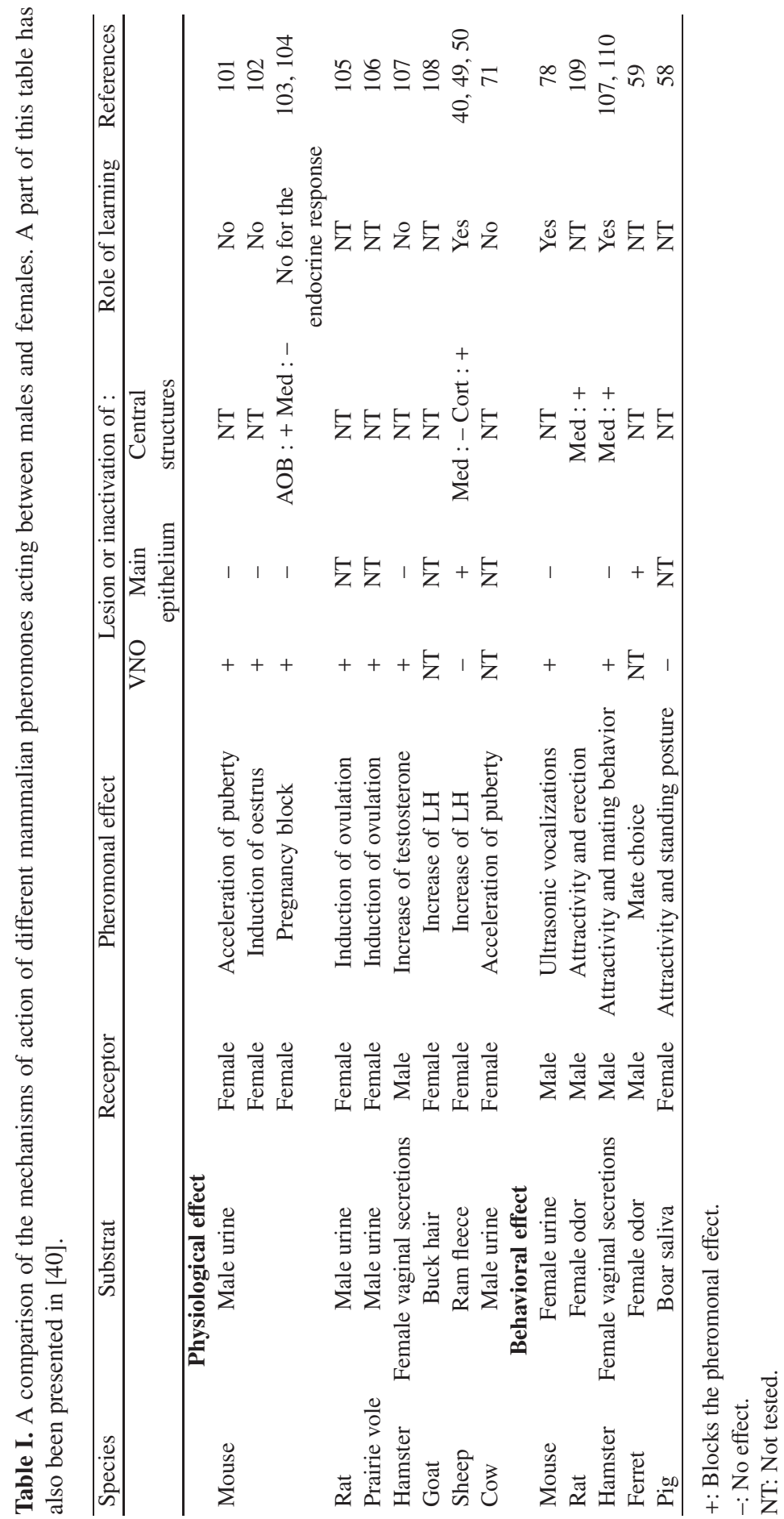


A

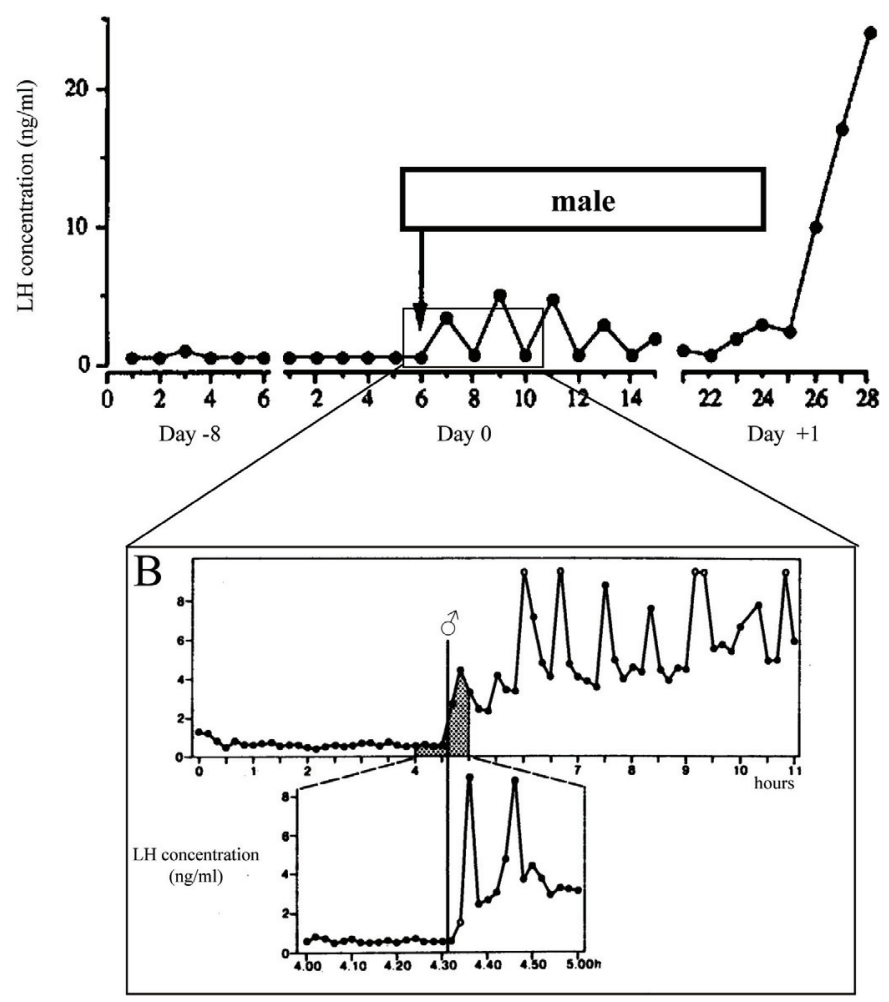

Figure 1. LH variations with blood samples collected every 10 min (top) and every 2 min (bottom) in anoestrous ewes after ram introduction. (Adapted from [12] and Fabre-Nys and Martin, unpublished data. This figure has also been presented in [40].)

experience ovulation nor ovarian cycles. Exposure to a ram results in activation of the LH secretion, and a pulse of $\mathrm{LH}$ is observed within minutes whereas the secretion of FSH or prolactin does not undergo such rapid changes [31-33] (Fig. 1). If the contact with males is maintained, ewes experience a preovulatory surge of $\mathrm{LH}$ which takes place at around $36 \mathrm{~h}$ (ranging from 6 to $54 \mathrm{~h}$, [34]). Simultaneously, a rise in the concentration of FSH occurs [35]. The point of ovulation is observed around $48 \mathrm{~h}$ after the introduction of the male and is qualified as "silent" because it is not associated with estrous behavior [34]. In half of the females, the develop- ment of the first corpus luteum is abnormal and regresses after 6-7 days, and the ewes re-cycle. Many of these ovulations are also silent [36]. Sexual behavior appears with subsequent ovulations and takes place in the form of two peaks of activity in the flock 18 and 25 days after the introduction of the male [36].

A direct contact with the male is not necessary to observe the increase of $\mathrm{LH}$ secretion since its effect can be in part mimicked by presentation of only its odor [22]. The active chemosignal is a mixture of compounds which have only been partially identified. The biological activity requires the simultaneous presence of compounds 
retained in both acid and neutral fractions [37]. According to the definition of Karlson and Lüscher [38] and Wilson and Bossert [39], the ram odor may be classified as a primer pheromone, a substance secreted by an individual and eliciting a specific physiological change in a second individual of the same species. However, like most of the mammalian pheromones, the ram odor does not strictly adhere to all of the criteria defining a pheromone.

\subsection{Behavioral response}

The physiological changes induced by the male or its odor have been extensively studied. To know if these stimuli can also modify the females' behavior, we completed an experiment to observe in detail the behavior of ewes during exposure to the ram or its fleece. Preliminary observations were carried out to establish a precise ethogram consisting of a classification of all behaviors into six principal components: investigation of the stimulus, locomotor activity, indicators of stress, indicators of attention, feeding behavior, other activity [40]. Then, we recorded all the behaviors displayed by three groups of anestrous ewes that were randomly exposed to female fleece, male fleece or rams.

Ear movements in sheep are associated with the "psychological state" of the animal. In a vigilant and attentive state, sheep keep their ears pricked as opposed to backwards. In the presence of the male or its fleece, most ewes keep their ears pricked whereas the proportion of ewes with ears backward is significantly higher in the presence of female fleece rather than male fleece or the male himself [40]. Furthermore, ewes tend to look more often at the male fleece than the female fleece. These observations suggest that the ram or its odor can stimulate the ewes' attention. A link between behavioral and endocrine response remains possible, with only ewes that are vigilant or attentive during the presentation of these stimuli exhibiting endocrine responses.

The proportion of ewes urinating and the number of urinations were significantly higher during exposure to male or its fleece than during exposure to female fleece. Emission of urine only with male fleece and not with female fleece shows that ewes can discriminate between both odors, and that the male or its odor induces these behavioral changes. Similar observations are obtained in rodents. In mice, females urinate more frequently in the presence of the male or its odor than in the presence of female odor [41]. In hamsters, male odor, on the contrary to female odor, increases vaginal marking behavior [42]. By urinating, ewes may signal to males their physiological state since rams are able to distinguish between urine of receptive and non receptive females [43].

Most ewes investigated at least once the two fleeces or the male but the total number of olfactory investigations did not differ between the three stimuli. This suggests that neither the male nor its fleece are attractive for ewes. In many species, odor from the opposite sex is attractive and can induce appetitive or copulatory behaviors (Tab. I). However, in most species, females are more attracted and interested by the male odor around the estrous period: rat [14], dog [44], pig [45], elephant [46]. In the context of the male effect, no ewes exhibited signs of receptivity. Our results show that male nudges were never followed by immobilizations or standing posture, characteristic of receptive behavior and acceptance of mating [47]. So, the ineffective attractiveness of the ram or its odor may be explained by the physiological state of ewes since they were in anestrus and they did not exhibit any sexual motivation.

In conclusion, our results show that the ram or its odor does not induce drastic behavioral changes, in particular they do 
not elicit strong attraction but seem to focus the attention of ewes and induce urine emission.

\section{NEURAL PATHWAYS INVOLVED IN THE EFFECT OF THE MALE OR ITS ODOR}

We used different procedures to assess the neural pathways involved in the effect of the male or its odor on the LH secretion of ewes. Firstly, to obtain a map of the brain areas activated by these stimuli, we used immunocytochemistry to examine the expression of the Fos protein, a marker of neuronal activation, in the brains of four groups of ewes exposed to different stimulations: male, male fleece, female fleece or the testing room (control group). In comparison with the control group, the male or its odor significantly increases Fos neuronal expression in the MOB and the $\mathrm{AOB}$, anterior olfactory nucleus, cortical and basal amygdala, dentate gyrus, ventromedial nucleus of the hypothalamus, piriform and orbitofrontal cortices [48]. The MOB, the cortical amygdala and the dentate gyrus are specifically more activated by the male odor than the female odor. These results demonstrate that the structures belonging to the main olfactory system play a critical role in the detection and the integration of the male olfactory cue. The Fos neuronal expression detected in the AOB shows that the accessory olfactory system participates in the detection of the ram odor, even if its involvement seems limited.

Then, we adopted a functional approach and we tested the effects of lesion or inactivation of different neuronal relays belonging to the main or the accessory system. Our results confirm the respective role of the two olfactory systems. Indeed, destruction of the olfactory epithelium (by intranasal administration of zinc sulfate) or inactivation of the cortical amygdala (by retrodialysis infusion of the anaesthetic lidocaine) completely blocks the endocrine response to ram odor $[40,49]$ (Tab. II). In contrast, lesion of the VNO or inactivation of the medial amygdala or the ventromedial nucleus of the hypothalamus does not impair the effect of ram odor on LH secretion $[49,50]$. These results show that the main olfactory system, on the contrary to the accessory system, is absolutely necessary for the detection and the integration of male olfactory cues. It is interesting to note that none of these surgical interventions affected the LH response to the male himself $[19,40]$ (Tab. II). These findings emphasize the role of sensory cues other than olfaction, but also suggest that other odors than those contained in the male fleece could account for a pheromonal activity and could be detected and processed by different neural pathways.

In rodents, pheromonal cues are frequently detected and processed by the vomeronasal neural pathway [51]. In the mouse and rat, sexual partner odor induces Fos activation only in the AOB and not the MOB $[52,53]$. In males and females, the destruction of the VNO blocks the endocrine changes provoked by urine of the opposite sex [54-56]. There are few examples in which chemical signals of the communication between individuals are essentially detected by the main olfactory epithelium. This is the case for the mother pheromone inducing nipple search in newborn rabbits [57] or for the boar saliva eliciting standing posture in female pigs [58]. In ferrets, nare occlusion eliminates heterosexual mate choice, suggesting a preponderant role of the main olfactory system in the processing of cues involved in the ferret mate recognition [59]. However, all of these examples imply olfactory signals inducing behavioral responses, whereas primer pheromones are mainly detected by the VNO (Tab. I).

In summary, our results show that in sheep, on the contrary to other species, 
Table II. Summary of the main results showing the neural pathways involved in the male effect. Destruction of the main olfactory epithelium and inactivation of the cortical nucleus of amygdala blocks the endocrine response to the male odor. In contrast, destruction of the vomeronasal organ (VNO), section of the vomeronasal (VN) nerves or inactivation of the medial amygdala has no effect. None of these surgical procedures impair the endocrine response to the male.

\begin{tabular}{lcccc}
\hline & \multicolumn{2}{c}{ Response to the male odor } & \multicolumn{2}{c}{ Response to the male } \\
\hline Structure & Control & Lesion or inactivation & Control & Lesion or inactivation \\
\hline Main olfactory system & & & & \\
Olfactory epithelium & $10 / 13$ & $3 / 13 *$ & $9 / 13$ & $11 / 13$ \\
Cortical amygdala & $6 / 9$ & $0 / 9 *$ & $3 / 6$ & $5 / 6$ \\
Accessory olfactory system & & & & $\mathrm{NT}$ \\
VNO Electrocauterization & $7 / 12$ & $8 / 12$ & & $\mathrm{NT}$ \\
VN nerves section & $7 / 10$ & $7 / 10$ & $5 / 9$ & $6 / 9$ \\
Medial amygdala & $6 / 10$ & $6 / 10$ & & \\
\hline
\end{tabular}

Data are expressed in the number of females exhibiting an LH increase in response to the stimulus.

* Different from the control group.

NT: Not tested.

the main olfactory system is mediating the detection of an olfactory message eliciting a physiological response. However, ram odor induces neuronal Fos responses in both the AOB and the MOB. This suggests that, even if the accessory system plays a minor role, it can participate in the detection and the integration of male olfactory cues. Similar data were obtained in male hamsters in which $\mathrm{AOB}$ and MOB neuronal Fos activation were observed in response to female vaginal secretions [60]. In this species, both olfactory systems are involved in the detection of sexual chemosignals, especially after sexual experience [61]. Similar implication of olfactory systems can occur in sheep.

\section{ROLE OF LEARNING}

The initial definition of pheromones requires that pheromones should elicit preprogrammed responses which are minimally influenced by experience [38]. However, this term was initially defined in insects and its extension to mammals raises some problems [62]. Indeed, in mammals, most behavioral responses elicited by sex- ual pheromones are facilitated by previous sexual experience. In many species, chemical signals serve as sexual attractants and promote appetitive and mating behaviors but these responses are preferentially expressed by sexually experienced individuals. In adult male rats, mice and dogs, sexual experience results in a preference for estrous over nonestrous female odors [63-65]. In mice, the presentation of female urine attracts and elicits vocalizations only in sexually experienced males $[65,66]$. Similarly, the odor of estrous female rats produces erection only in sexually experienced males [67]. In contrast, most chemosignals eliciting physiological changes are effective in naive individuals never exposed before to the emitter. In several species, male odors accelerate puberty in young females that have never been in contact with males, for example: mouse [68], prairie vole [69], hamster [70], and cow [71]. In hamsters, female vaginal secretions induce an increase of testosterone in sexually naive males [72]. Naive male mice also reflexively release luteinizing hormone (LH) and testosterone pulses after encountering a female or her urinary pheromones $[73,74]$. 
In rodents, pheromonal cues are essentially detected and integrated by the accessory olfactory system $[28,51,75]$. Destruction of the VNO eliminates most responses to conspecific odors [76]. However, in some cases, learning can compensate for the dramatic effects of the VNO lesion. In male hamsters, lesion of the VNO produces severe deficits in mating behavior in sexually naive males but have little effect in experienced males [77]. Destruction of the VNO of male mice eliminates vocalizations in response to female urine but only in sexually naive individuals [78]. In contrast, concerning primer pheromones, the compensation of the lesion of the VNO by sexual experience does not appear possible [29]. For example, the destruction of the VNO impairs the surge of LH and testosterone elicited by female odor in both sexually naive and experienced males $[55,56]$. In sheep, lesion of the VNO does affect the $\mathrm{LH}$ response to the male odor [50]. However, this result has been obtained in sexually experienced ewes and it remains possible that learning processes can compensate for the VNO lesion. But before testing the effect of VNO lesion in sexually naive ewes, the ability of naive females to respond to the male odor had to be evaluated.

Another argument that conducts us to assess the role of sexual experience came from our data showing the neural pathways involved in the effect of the male or its odor. The neural pathway of the accessory system can be considered as direct since this system is essentially connected to hypothalamic structures and not to the cognitive centers of the brain. For this reason, it has been postulated that the chemosignals detected and integrated by the accessory system do not require learning mechanisms in order to be effective and would induce preprogrammed and stereotyped responses. In contrast, the numerous cortical areas belonging to the main olfactory system could provide for an elaborate treatment of the olfactory cues. The olfactory amygdala which is connected to several cortical areas, can access higher levels of olfactory processing than the vomeronasal amygdala which projects only to hypothalamic structures. The piriform and the entorhinal cortex, and the basolateral nucleus of the amygdala (which has cross connections with the cortical nucleus) are involved in memory and learning processes, including olfactory discrimination [79-81]. In our study, Fos neuronal activation detected in these structures after exposure to the male or its fleece suggests their involvement in the detection of the male odor. Furthermore, the results of our study testing the effect of lesion or inactivation of different relays belonging to the two olfactory systems demonstrate the critical role of the main olfactory system. This system would provide for elaborate cognitive processing of the information. Accordingly, we hypothesized that the response to the male or its odor could be modulated by previous experience and learning processes. To examine this question, we completed two experiments.

\subsection{Role of sexual experience}

The aim of this experiment was to compare the LH responses to the ram and its odor between sexually naive or experienced ewes. Our previous findings showed that age and sexual experience can differently affect ewe sexual behavior. Indeed, during their first interaction with males, sexually naive both young and adult females do not display proceptive behaviors whereas sexually naive adult ewes, on the contrary to naive young females, exhibit levels of receptivity similar to experienced adults [82]. These results prove the importance of dissociating the effect of these two factors. For this reason, we used 4 groups of females that differed by their sexual experience (sexually naive or experienced) 


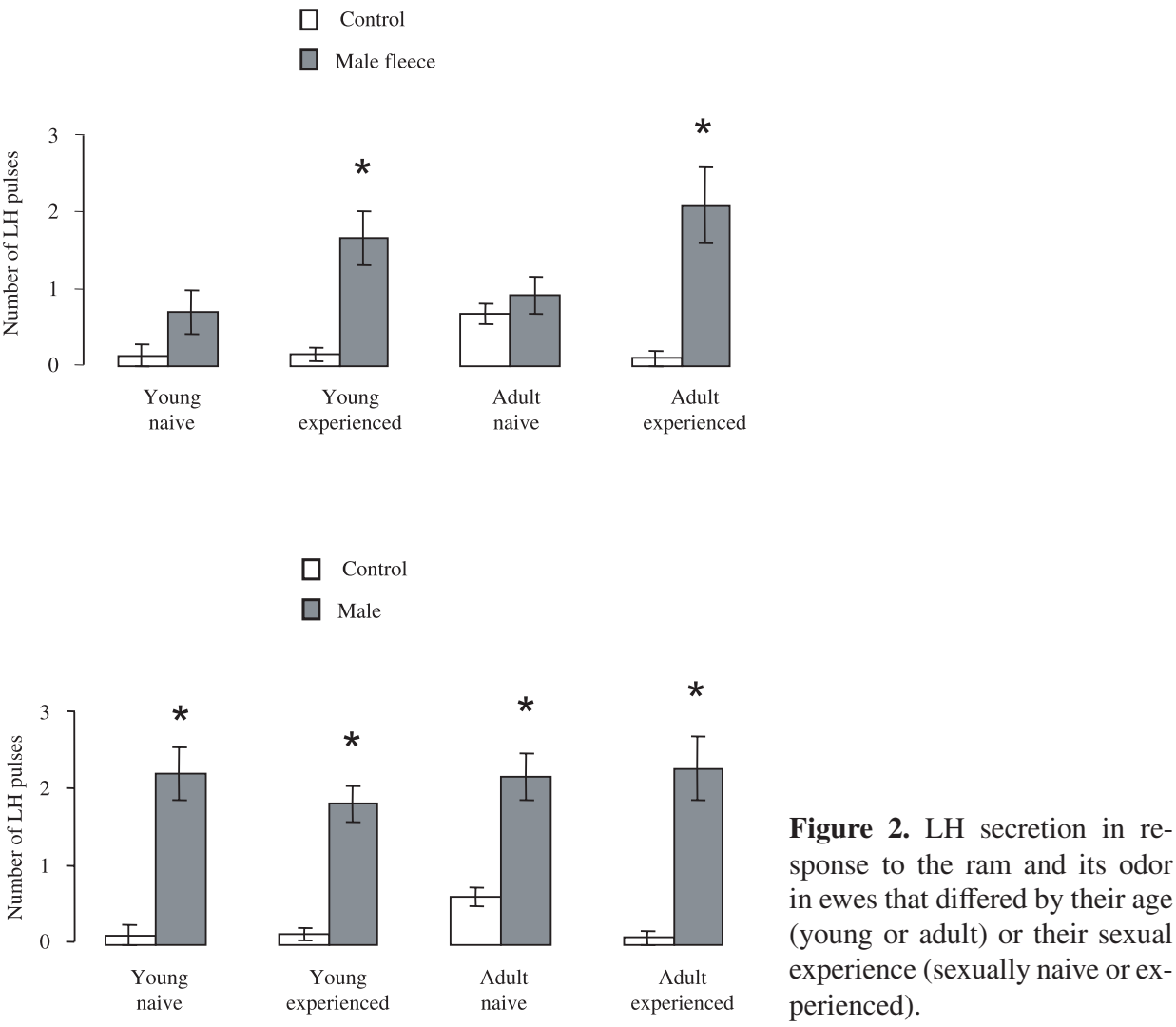

and their age (young or adult). All the females were randomly exposed to female fleece, male fleece or males.

\subsubsection{Response to male odor}

Our results show that the male odor activates $\mathrm{LH}$ secretion in sexually experienced ewes both young and adult, but has no effect in most naive females [83] (Fig. 2). The experienced ewes, regardless of their age, exhibited a significantly greater number of LH pulses during exposure to the male odor than during exposure to the female fleece. No significant increase of LH pulses was detected in naive females. The response latency was also significantly shorter for the experienced ewes. These findings demonstrate that sexual experience is a critical factor and facilitates the endocrine response to the ram odor. This markedly differs from other species. Indeed, in most mammals, the effects of olfactory cues on neuroendocrine secretions are independent of previous sexual experience and do not require learning mechanisms. The male odor accelerates sexual maturation in young females which have never been in contact with males (mouse [84], prairie vole [69], hamster [70], cow [71]). Sexually naive males exhibit a reflexive increase of testosterone during their first exposure to female urine or vaginal secretion (mouse [74], hamster [72]). In sheep, on the contrary to rodents, it seems that the male odor needs to be learned to be effective. This suggests that sexual 
experience is required to recognize the ram odor and to give meaning to this olfactory signal. In contrast, exposure to the male himself results in activation of the $\mathrm{LH}$ secretion in all ewes, regardless of their experience or their age (Fig. 2). The male appears as a sufficiently powerful stimulus to modify the female LH secretion immediately, without prior exposure or sexual experience.

The analysis of the female behaviors reveals that both groups of experienced ewes investigated significantly more (number of olfactory investigations and number of times they "ate" the fleece) the male than the female fleece. These differences were not observed in the two groups of naive females, excepting that the naive adult ewes investigated more the male than the female fleece. These results suggest that the male odor does not possess innate attractive properties, on the contrary to some species (hamster [85], mouse [86, 87]). Only the sexually experienced ewes urinated more in the presence of the ram fleece than the female fleece. This suggests that the emission of urine is not a pre-programmed response but rather a response to an identified stimulus. In ungulates, the emission of urine by females is frequent during sexual interactions and is commonly followed by male flehmen $[88,89]$. In most breeds, the females urinate more in response to male courtship when they were in anestrus rather than in estrus [90,91]. In another breed of sheep, Romanov, and in goats, however, females urinated more in the presence of males when they were in estrus (Fabre-Nys, personal observation). This behavior can serve to attract males and stimulate their sexual arousal, and may be considered a sign of proceptivity similar to vaginal marking by female hamsters [92]. This same explanation is not applicable to our results since in the context of the male effect, ewes are in anestrus. The exact significance of female urine emission therefore remains unclear.

\subsubsection{Response to male}

In the presence of males, naive ewes exhibited an LH response similar to those of the experienced females and the LH response did not differ significantly among four groups of females. For all groups of females, the proportion of responsive ewes, the number of $\mathrm{LH}$ pulses and the maximum concentration of LH were significantly higher during exposure to males than during exposure to the female fleece. These results suggest that the male, on the contrary to its fleece alone, constitutes a sufficiently powerful stimulation that does not require prior sexual experience. These findings emphasize the importance of sensory information other than olfaction in the processes of the male effect. This has been previously demonstrated since bulbectomy does not impair the LH increase elicited by the male [93]. Furthermore, castrated rams or females treated with testosterone can induce ovulation in anestrous ewes [94]. Our results confirm these data since none of the interventions which eliminate the endocrine response to the male odor have an effect on the response to the male himself. When the male is presented, the destruction of the olfactory epithelium or the inactivation of the cortical amygdala does not disrupt the increase of LH [49].

\subsection{Associative olfactory learning}

The results of the previous experiment show that the ram odor has to acquire a meaning for the females, in order to induce the endocrine response. During their first interactions with males, ewes could proceed to an associative olfactory learning between the male and its odor, to be able to subsequently respond to the odor alone. This olfactory associative learning can follow the rules of a pavlovian conditioning consisting of the association between an unconditioned (the male) and a 
conditioned stimuli (the ram odor). Afterwards, the conditioned cue could mimic the effect of the unconditioned stimulus. To assess this hypothesis, we tested the effectiveness of a neutral conditioned stimulus (lavender odor) previously associated with the male, to induce the endocrine and behavioral responses. During the breeding season, three groups of ewes were placed for two weeks with either males scented with lavender, unscented males or females scented with lavender. Then, during the anestrous period, all ewes were randomly exposed to unscented female fleece or female fleece scented with lavender. Our results show that the lavender odor induced an LH increase in a large proportion of ewes that had been previously in contact with males scented with lavender (Fig. 3). The females of this group showed a significantly greater number of LH pulses and a high LH maximum during exposure to the scented fleece than during exposure to the unscented fleece. The same effect was not observed in the two other groups of females (Fig. 3). The lavender odor also tended also to mimic the behavioral effect of the male odor. Indeed, only the ewes previously exposed to scented males tended to urinate more during exposure to the lavender scented fleece than in the presence of the unscented fleece.

Similar conditioning paradigms have been used to reproduce behavioral changes induced by chemosignals. For example, when mating occurs with females scented with an artificial odor, subsequent exposure to this odor induces vocalizations by male mice [95] and rats develop a preference for a sexual partner treated with this scent $[96,97]$. In contrast, conditioned endocrine responses are difficult to obtain [29], and this has only been demonstrated in one study. Graham and Desjardins [98] showed that male rats exhibit an increase in circulating levels of $\mathrm{LH}$ and testosterone in response to an artificial odor (methylsalicylate) which had been previously paired

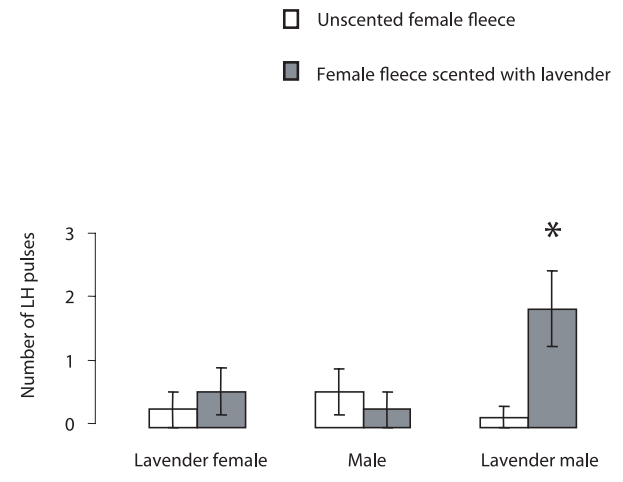

Figure 3. LH secretion in response to a neutral odor (lavender odor) in ewes previously exposed to females scented with lavender, unscented males or males scented with lavender.

with a receptive female during mating. In our experiment, the activation of $\mathrm{LH}$ secretion and the emission of urine in the response to the lavender odor suggest that the females have learned the association between the ram and the artificial odor. A similar associative olfactory learning between the sexual partner and its odor can occur during the first interactions with males, leading to assign a "meaning" to the male chemosignal.

\section{CONCLUSION}

Our results demonstrate the critical role of sexual experience in the endocrine response to the ram odor and suggest that olfactory associative learning mechanisms can occur during first interactions with males, giving the capability of ewes to subsequently recognize the male fleece. Our findings support the idea that processes of olfactory cues detected by the main olfactory system can involve cognitive or learning mechanisms. The response to the ram odor does not correspond to preprogrammed or reflex responses, but rather responses to a stimulus that had acquired 
a meaning. It is interesting to note that in other species, all the chemosignals that are integrated by the main olfactory system and require learning mechanisms, concern only behavioral responses (pig [58], ferret [99]). In comparison, the ram odor constitutes an original model of action of a primer pheromone. This may correspond to an adaptative strategy of reproduction that would be advantageous for species living in variable conditions with seasonal breeding and high predator pressure.

\section{ACKNOWLEDGEMENTS}

The authors thank Didier Chesneau, Eric Archer and Raymond Campan for their help and their technical assistance.

\section{REFERENCES}

[1] McClintock MK. Estrous synchrony and its mediation by airborne chemical communication (Rattus norvegicus). Horm Behav 1978, 10: 264-275.

[2] Van Der Lee S, Boot LM. Spontaneous pseudopregnancy in mice. Acta Physiol Pharmacol Neerl 1955, 4: 442-444.

[3] Whitten WK. Occurrence of anoestrus in mice caged in groups. J Endocrinol 1959, 18: 102-107.

[4] Lawton AD, Whitsett JM. Inhibition of sexual maturation by a urinary pheromone in male prairie deer mice. Horm Behav 1979, 13: $128-138$.

[5] Vandenbergh JG. Effect of the presence of a male on the sexual maturation of female mice. Endocrinology 1967, 81: 345-349.

[6] Vandenbergh JG. The influence of the social environment on sexual maturation in male mice. J Reprod Fertil 1971, 24: 383-390.

[7] Whitten WK. Modification of the oestrous cycle of the mouse by external stimuli associated with the male. J Endocrinol 1956, 13: 399-404.

[8] Bruce HM. A block to pregnancy in the mouse caused by proximity of strange males. J Reprod Fertil 1960, 1: 96-103.

[9] Macrides F, Bartke A, Fernandez F, D'Angelo W. Effects of exposure to vaginal odor and receptive females on plasma testosterone in the male hamster. Neuroendocrinology 1974, 15: 355-364.

[10] Ryan KD, Schwartz NB. Changes in serum hormone levels associated with maleinduced ovulation in group-housed adult female mice. Endocrinology 1980, 106: 959966.

[11] Chemineau P. Effect on oestrus and ovulation of exposing creole goats to the male at three times of the year. J Reprod Fertil 1983, 67: 65-72.

[12] Martin GB, Oldham CM, Cognié Y, Pearce DT. The physiological responses of anovulatory ewes to the introduction of rams - A review. Livest Prod Sci 1986, 15: 219-247.

[13] Thimonier J, Cognié Y, Lassoued N, Khaldi G. L'effet mâle chez les ovins : une technique actuelle de maîtrise de la reproduction. INRA Prod Anim 2000, 13: 223-231.

[14] Brown RE. Odor preference and urinemarking scales in male and female rats: effects of gonadectomy and sexual experience on responses to conspecifics odors. J Comp Physiol Psychol 1977, 91: 1190-1206.

[15] Johnston RE, Bronson F. Endocrine control of female mouse odors that elicit luteinizing hormone surges and attraction in males. Biol Reprod 1982, 27: 1174-1180.

[16] Petrulis A, Johnston RE. A reevaluation of dimethyl disulfide as a sex attractant in golden hamsters. Physiol Behav 1995, 57: 779-784.

[17] Rasmussen LE, Lee TD, Zhang A, Roelofs WL, Daves GD Jr. Purification, identification, concentration and bioactivity of (Z)-7dodecen-1-yl acetate: sex pheromone of the female Asian elephant, Elephas maximus. Chem Senses 1997, 22: 417-437.

[18] Michael RP, Keverne EB. Primate sex pheromones of vaginal origin. Nature 1970, 225: 84-85.

[19] Bronson FH. Serum FSH, LH, and prolactin in adult ovariectomized mice bearing silastic implants of estradiol: responses to social cues. Biol Reprod 1976, 15: 147-152.

[20] Kamel F, Wright WW, Mock EJ, Frankel AI. The influence of mating and related stimuli on plasma levels of luteinizing hormone, follicle stimulating hormone, prolactin, and testosterone in the male rat. Endocrinology 1977, 101: 421-429.

[21] Dluzen DE, Ramirez VD, Carter CS, Getz LL. Male vole urine changes luteinizing hormone-releasing hormone and norepinephrine in female olfactory bulb. Science 1981, 212: 573-575. 
[22] Knight TW, R LP. Source of ram pheromones that stimulate ovulation in the ewe. Anim Reprod Sci 1980, 3: 133136.

[23] Cohen-Tannoudji, J. Effet du mâle sur la sécrétion gonadotrope $(\mathrm{LH})$ de la brebis (Ovis aries L). Analyse de l'interaction olfactive. Thèse de doctorat, Université de Paris, 1988.

[24] Scalia F, Winans SS. The differential projections of the olfactory bulb and accessory olfactory bulb in mammals. J Comp Neurol 1975, 161: 31-55.

[25] Kevetter GA, Winans SS. Connections of the corticomedial amygdala in the golden hamster. II. Efferents of the "olfactory amygdala". J Comp Neurol 1981, 197: 99-111.

[26] Kevetter GA, Winans SS. Connections of the corticomedial amygdala in the golden hamster. I. Efferents of the "vomeronasal amygdala". J Comp Neurol 1981, 197: 81-98.

[27] Jansen HT, Iwamoto GA, Jackson GL. Central connections of the ovine olfactory bulb formation identified using wheat germ agglutinin-conjugated horseradish peroxidase. Brain Res Bull 1998, 45: 27-39.

[28] Brennan PA. The vomeronasal system. Cell Mol Life Sci 2001, 58: 546-555.

[29] Keverne EB. Non-olfactory chemoreceptors of the nose: recent advances in understanding the vomeronasal and trigeminal systems. Chem Senses 1986, 11: 119-133.

[30] Wysocki CJ, Bean NJ, Beauchamp GK. The vomeronasal system: its role in learning and social behaviour. In: Chemical signals in Vertebrates, Plenum Press, New York, 1986, p 471-485.

[31] Martin GB, Oldham CM, Lindsay DR. Increased plasma LH levels in seasonally anovular Merino ewes following the introduction of rams. Anim Reprod Sci 1980, 3: 125-132.

[32] Martin GB, Scaramuzzi RJ, Lindsay DR. Effect of the introduction of rams during the anoestrous season on the pulsatile secretion of LH in ovariectomized ewes. J Reprod Fertil 1983, 67: 47-55.

[33] Poindron P, Cognie Y, Gayerie F, Orgeur $\mathrm{P}$, Oldham CM, Ravault JP. Changes in gonadotrophins and prolactin levels in isolated (seasonally or lactationally) anovular ewes associated with ovulation caused by the introduction of rams. Physiol Behav 1980, 25: 227-236.

[34] Oldham CM, Martin GB, Knight TW Stimulation of the seasonally anovular
Merinos ewes by rams. I. Time from introduction of the rams to the preovulatory surge and ovulation. Anim Reprod Sci 1978, 1: 283-290.

[35] Martin GB, Scaramuzzi RJ. The induction of oestrus and ovulation in seasonally anovular ewes by exposure to rams. J Steroid Biochem 1983, 19: 869-875.

[36] Oldham CM, Martin GB. Stimulation of the seasonally anovular Merinon ewes by rams. II. Premature regression of ram-induced corpora lutea. Anim Reprod Sci 1978, 1: 291295.

[37] Cohen-Tannoudji J, Einhorn J, Signoret JP. Ram sexual pheromone: first approach of chemical identification. Physiol Behav 1994, 56: 955-961.

[38] Karlson P, Luscher M. Pheromones: a new term for a class of biologically active substances. Nature 1959, 183: 55-56.

[39] Wilson EO, Bossert WH. Chemical Communication among Animals. Recent Prog Horm Res 1963, 19: 673-716.

[40] Gelez H, Fabre-Nys C. The "male effect" in sheep and goats: a review of the respective roles of the two olfactory systems. Horm Behav 2004, 46: 257-271.

[41] Maruniak JA, Owen K, Bronson FH, Desjardins C. Urinary marking in female house mice: effects of ovarian steroids, sex experience and type of stimulus. Behav Biol 1975, 13: 211-217.

[42] Johnston RE. The causation of two scentmarking behaviour patterns in female hamsters (Mesocricetus auratus). Anim Behav 1977, 25: 317-327.

[43] Blissitt MJ, Bland KP, Cottrell DF. Discrimination between the odours of fresh oestrous and non-oestrous ewe urine by rams. Appl Anim Behav Sci 1990, 25: 51-59.

[44] Dunbar IF. Olfactory preferences in dogs: the response of male and female beagles to conspecific odors. Behav Biol 1977, 20: 471-481.

[45] Signoret JP. Reproductive behaviour of pigs. J Reprod Fertil Suppl 1970, 11: 105.

[46] Rasmussen LE, Greenwood DR. Frontalin: a chemical message of musth in Asian elephants (Elephas maximus). Chem Senses 2003, 28: 433-446.

[47] Fabre-Nys C, Venier G. Development and use of a method for quantifying female sexual behaviour in ewes. Appl Anim Behav Sci 1987, 17: 289-304. 
[48] Gelez H, Fabre-Nys C. Neural pathways involved in the endocrine response of anestrous ewes to the male or its odor. Neuroscience 2006 (in press).

[49] Gelez H, Archer E, Chesneau D, Magallon T, Fabre-Nys C. Inactivation of the olfactory amygdala prevents the endocrine response to male odour in anoestrus ewes. Eur J Neurosci 2004, 19: 1581-1590.

[50] Cohen-Tannoudji J, Lavenet C, Locatelli A, Tillet Y, Signoret JP. Non-involvement of the accessory olfactory system in the LH response of anoestrous ewes to male odour. J Reprod Fertil 1989, 86: 135-144.

[51] Keverne EB. Pheromonal influences on the endocrine regulation of reproduction. Trends Neurosci 1983, 6: 381-384.

[52] Halem HA, Cherry JA, Baum MJ. Vomeronasal neuroepithelium and forebrain Fos responses to male pheromones in male and female mice. J Neurobiol 1999, 39: 249-263.

[53] Kelliher KR, Liu YC, Baum MJ, Sachs BD. Neuronal Fos activation in olfactory bulb and forebrain of male rats having erections in the presence of inaccessible estrous females. Neuroscience 1999, 92: 1025-1033.

[54] Beltramino C, Taleisnik S. Release of LH in the female rat by olfactory stimuli. Effect of the removal of the vomeronasal organs or lesioning of the accessory olfactory bulbs. Neuroendocrinology 1983, 36: 53-58.

[55] Coquelin A, Clancy AN, Macrides F, Noble EP, Gorski RA. Pheromonally induced release of luteinizing hormone in male mice: involvement of the vomeronasal system. J Neurosci 1984, 4: 2230-2236.

[56] Wysocki CJ, Katz Y, Bernhard R. Male vomeronasal organ mediates female-induced testosterone surges in mice. Biol Reprod 1983, 28: 917-922.

[57] Hudson R, Distel H. Pheromonal release of suckling in rabbits does not depend on the vomeronasal organ. Physiol Behav 1986, 37: $123-128$.

[58] Dorries KM, Adkins-Regan E, Halpern BP. Sensitivity and behavioral responses to the pheromone androsterone are not mediated by the vomeronasal organ in domestic pigs. Brain Behav Evol 1997, 49: 53-62.

[59] Kelliher KR, Baum MJ. Nares occlusion eliminates heterosexual partner selection without disrupting coitus in ferrets of both sexes. J Neurosci 2001, 21: 5832-5840.
[60] Fiber JM, Adames P, Swann JM. Pheromones induce c-fos in limbic areas regulating male hamster mating behavior. Neuroreport 1993, 4: 871-874.

[61] Fewell GD, Meredith M. Experience facilitates vomeronasal and olfactory influence on Fos expression in medial preoptic area during pheromone exposure or mating in male hamsters. Brain Res 2002, 941: 91-106.

[62] Beauchamp GK, Doty RL, Moulton DG, Mugford RA. The pheromone concept in mammalian chemical communication: a critique. Doty RL (Ed), Academic Press, New York, 1976.

[63] Carr WJ, Loeb LS, Dissinger ML. Responses of rats to sex odors. J Comp Physiol Psychol 1965, 59: 370-377.

[64] Doty RL, Dunbar I. Attraction of beagles to conspecific urine, vaginal and anal sac secretion odors. Physiol Behav 1974, 12: $825-833$.

[65] Hayashi S, Kimura T. Sex-attractant emitted by female mice. Physiol Behav 1974, 13: 563-567.

[66] Dizinno G, Whitney G, Nyby J. Ultrasonic vocalizations by male mice (Mus musculus) to female sex pheromone: experiential determinants. Behav Biol 1978, 22: 104-113.

[67] Sachs BD. Erection evoked in male rats by airborne scent from estrous females. Physiol Behav 1997, 62: 921-924.

[68] Colby DR, Vandenberg JG. Regulatory effects of urinary pheromones on puberty in the mouse. Biol Reprod 1974, 11: 268-279.

[69] Carter CS, Getz LL, Gavish L, McDermott JL, Arnold P. Male-related pheromones and the activation of female reproduction in the prairie vole (Microtus ochrogaster). Biol Reprod 1980, 23: 1038-1045.

[70] Reasner DS, Johnston RE. Acceleration of reproductive development in female Djungarian hamsters by adult males. Physiol Behav 1988, 43: 57-64.

[71] Izard MK, Vandenbergh JG. The effects of bull urine on puberty and calving date in crossbred beef heifers. J Anim Sci 1982, 55: 1160-1168.

[72] Pfeiffer CA, Johnston RE. Hormonal and behavioral responses of male hamsters to females and female odors: roles of olfaction, the vomeronasal system, and sexual experience. Physiol Behav 1994, 55: 129-138. 
[73] Macrides F, Bartke A, Dalterio S. Strange females increase plasma testosterone levels in male mice. Science 1975, 189: 1104-1106.

[74] Maruniak JA, Bronson FH. Gonadotropic responses of male mice to female urine. Endocrinology 1976, 99: 963-969.

[75] Keverne EB. The vomeronasal organ. Science 1999, 286: 716-720.

[76] Wysocki CJ, Lepri JJ. Consequences of removing the vomeronasal organ. J Steroid Biochem Mol Biol 1991, 39: 661-669.

[77] Meredith M. Vomeronasal organ removal before sexual experience impairs male hamster mating behavior. Physiol Behav 1986, 36: 737-743.

[78] Bean NJ. Olfactory and vomeronasal mediation of ultrasonic vocalizations in male mice. Physiol Behav 1982, 28: 31-37.

[79] Datiche F, Roullet F, Cattarelli M. Expression of Fos in the piriform cortex after acquisition of olfactory learning: an immunohistochemical study in the rat. Brain Res Bull 2001, 55: 95-99.

[80] Hess US, Gall CM, Granger R, Lynch G. Differential patterns of c-fos mRNA expression in amygdala during successive stages of odor discrimination learning. Learn Mem 1997, 4: 262-283.

[81] Tronel S, Sara SJ. Mapping of olfactory memory circuits: region-specific c-fos activation after odor-reward associative learning or after its retrieval. Learn Mem 2002, 9: $105-111$.

[82] Gelez H, Archer E, Chesneau D, Lindsay D, Fabre-Nys C. Role of experience in the neuroendocrine control of ewes' sexual behavior. Horm Behav 2004, 45: 190-200.

[83] Gelez H, Archer E, Chesneau D, Campan R, Fabre-Nys C. Importance of learning in the response of ewes to male odor. Chem Senses 2004, 29: 555-563.

[84] Vandenbergh JG. Male odor accelerates female sexual maturation in mice. Endocrinology 1969, 84: 658-660.

[85] Johnston RE. Sexual attraction function of golden hamster vaginal secretion. Behav Biol 1974, 12: 111-117.

[86] Jemiolo B, Xie TM, Novotny M. Sociosexual olfactory preference in female mice: attractiveness of synthetic chemosignals. Physiol Behav 1991, 50: 1119-1122.
[87] Moncho-Bogani J, Lanuza E, Hernandez A, Novejarque A, Martinez-Garcia F. Attractive properties of sexual pheromones in mice: innate or learned? Physiol Behav 2002, 77: 167-176.

[88] Banks EM. Some aspects of sexual behavior in domestic sheep, Bovis aries. Behav 1964, 23: 249-279.

[89] Ladewig J, Price EO, Hart BL. Flehmen in male goats: role in sexual behavior. Behav Neural Biol 1980, 30: 312-322.

[90] Bland KP, Jubilan BM. Correlation of flehmen by male sheep with female behaviour and oestrus. Anim Behav 1987, 35: 735-738.

[91] Stevens K, Perry GC, Long SE. Effect of ewe urine and vaginal secretions on ram investigative behaviour. J Chem Ecol 1982, 8: 23-28.

[92] Johnston RE. Olfactory preferences, scent marking, and "proceptivity" in female hamsters. Horm Behav 1979, 13: 21-39.

[93] Cohen-Tannoudji J, Locatelli A, Signoret JP. Non-pheromonal stimulation by the male of $\mathrm{LH}$ release in the anoestrous ewe. Physiol Behav 1986, 36: 921-924.

[94] Signoret JP, Fulkerson WJ, Lindsay DR. Effectiveness of testosterone treated wethers and ewes as teasers. Appl Anim Ethol 1982, 9: $37-45$.

[95] Nyby J, Whitney G, Schmitz S, Dizinno G. Postpubertal experience establishes signal value of mammaliam sex odor. Behav Biol 1978, 22: 545-552.

[96] Kippin TE, Pfaus JG. The development of olfactory conditioned ejaculatory preferences in the male rat. I. Nature of the unconditioned stimulus. Physiol Behav 2001, 73: 457-469.

[97] Kippin TE, Pfaus JG. The nature of the conditioned response mediating olfactory conditioned ejaculatory preference in the male rat. Behav Brain Res 2001, 122: 11-24.

[98] Graham JM, Desjardins C. Classical conditioning: induction of luteinizing hormone and testosterone secretion in anticipation of sexual activity. Science 1980, 210: 10391041.

[99] Kelliher KR, Chang YM, Wersinger SR, Baum MJ. Sex difference and testosterone modulation of pheromone-induced Neuronal Fos in the Ferret's main olfactory bulb and hypothalamus. Biol Reprod 1998, 5: 1454 1463. 